\title{
Association of insecticide use and alteration on Aedes aegypti susceptibility status
}

\author{
Maria de Lourdes da Graça Macoris/ ${ }^{+}$, Maria Teresa Macoris Andrighetti, \\ Vanessa Camargo Garbeloto Otrera, Lídia Raquel de Carvalho*, \\ Antonio Luiz Caldas Júnior**, William G Brogdon***
}

Superintendência de Controle de Endemias, SUCEN, Núcleo de Pesquisa SR 11/Marília, Av. Santo Antonio 1627, 17506-040 Marília, São Paulo, Brasil *Instituto de Biociências **Faculdade de Medicina, Universidade Estadual Paulista, Botucatu, São Paulo, Brasil

$* * *$ Centers for Disease Control and Prevention, Atlanta GA, USA

Dengue and dengue hemorrhagic fever, vector-borne diseases transmitted by the mosquito Aedes aegypti, are presently important public health problems in Brazil. As the strategy for disease control is based on vector control through the use of insecticides, the development of resistance is a threat to programs efficacy. The objective of this study was to compare the Aedes aegypti susceptibility in nine vector populations from the state of São Paulo and seven from Northeast region of Brazil, since there was a difference on group of insecticide used between the areas. Bioassays with larvae and adult were performed according to the World Health Organization methods. The results showed higher resistance levels to organophosphates group in populations from the Northeast region where this group was used for both larvae and adult control than in São Paulo where organophosphates were used for larvae and pyretroids for adult control. Resistance to pyretroids in adults was widespread in São Paulo after ten years of use of cypermethrin while in vector populations from the Northeast region it was punctual. The difference in resistance profile between the areas is in accordance to the group of insecticide used.

Key words: Aedes aegypti - resistance to insecticides - vector control

Since their inception in the 1980s, Brazilian Dengue Control Programs have proposed integrated vector control, with sanitation measures, source reduction, community education and participation (Funasa 1994, 1996). However, control activities have almost all been centered on chemical control by applying insecticides to eliminate larvae and adults. In 1995, a wider approach to the problem was attempted with the national plan for eradication of Aedes aegypti. It proposed environmental sanitation activities, communication and social mobilization and direct combat against the vector (Sucen 1997, 2002). Among all proposed activities, the one that was extensively implanted was the introduction of municipal teams for house-by-house vector control with chemical larvicide.

For adult control, evidence of dengue transmission triggered space spraying activities. With the introduction of the Brazilian eradication plan in 1997/1998, there was an increase in insecticide use especially in two regions where dengue incidence was higher: the Southeast, including the state of São Paulo (SP), and the Northeast regions.

Chemical control effectiveness is threatened by the development of resistance to insecticides as seen in lit-

Financial support: Superintendência de Controle de Endemias (SUCEN)

${ }^{+}$Corresponding author: macoris@sucen.sp.gov.br

Received 20 February 2007

Accepted 9 November 2007 erature for Ae. aegypti (Georghiou et al. 1987, Rawlins 1998, Wirth \& Georghiou 1999, Lima et al. 2003).

Since the 1980s all Brazilian states have adopted the routine use of an organophosphate larvicide (1\% temephos in sand granules) (Funasa 1994, 2001, Sucen 1997). Thermal fog and cold aerosols have been used since 1985 for space spraying using malathion until 1999. In SP focal treatment with temephos started in 1985 along with residual treatment with fenitrothion, another organophosphate insecticide. The history of insecticide use in other Brazilian states was similar to SP except for the choice of adulticides. While SP introduced cypermethrin in 1989, the others used malathion and fenitrothion until 1999. Thus there was a 10 -year difference in the introduction of pyretroids for adult control between SP and the other states. The choice for pyretroids for adult control in SP was based on environmental concerns which led to the option for the least toxic class of insecticide.

Considering the difference in selection pressure for resistance, susceptibility levels were evaluated for $A e$. aegypti populations in SP and states in the Northeast of the country. The opportunity of studying the impact of using different insecticide groups on population susceptibility can help understanding its role in resistance development and it may also support the choice of product use to improve vector control effectiveness.

\section{MATERIALS AND METHODS}

Sampling Ae. aegypti populations for susceptibility evaluation - Ae aegypti populations were sampled in counties which integrate the Brazilian National Suscep- 
tibility Monitoring Program and sampling methodologies are described in Lima et al. $(2003,2006)$ and Macoris et al. (2003). Nine counties from SP were sampled: Araçatuba, Bauru, Barretos, Campinas, Marília, Presidente Prudente, Ribeirão Preto, São José do Rio Preto, and Santos. To represent areas where insecticide use was different from SP, seven populations were sampled from the states of Alagoas (Arapiraca and Maceió), Pernambuco (Recife and Jaboatão dos Guararapes), and Sergipe (Aracaju, Barra dos Coqueiros, and Itabaiana). All field sampling was performed in the second semester of 1999 by collecting eggs in ovitraps as described by Reiter (1991).

Bioassays for susceptibility evaluation - Larvae were evaluated for their susceptibility to temephos and fenitrothion and adults for malathion, cypermethrin, and permethrin. Bioassays were performed according to World Health Organization (WHO) guidelines (WHO 1981a,b,c,d). Larvae susceptibility was evaluated by estimating resistance ratio (RR). Larvae were exposed to a range of eight solution concentrations. Results were expressed in number of dead specimens per dose, and were statistically analyzed using the Polo-PC software (Lenora Software 1987) to estimate 50\% and 95\% lethal concentrations (LC50 and LC95), and their respective $95 \%$ confidence intervals calculated by the method of Robertson and Preisler (1992). Three complete tests were performed for each insecticide and each mosquito population. There were four replications of 20 larvae per dose. RR were calculated based on LC50 and LC95 estimated for the Rockefeller susceptible reference strain, gently provided by the Centers of Disease Control of Puerto Rico. Population comparisons were made by analyzing RR at LC95. Adult mosquitoes were evaluated by population response to $\mathrm{WHO}$ diagnostic dose proposals for malathion $(0.8 \% / 1 \mathrm{~h})$ and permethrin $(0.25 \% / 1 \mathrm{~h})$ (WHO 1992) using impregnated paper. The impregnated paper was gently provided by the Brazilian Ministry of Health and purchased at the WHO in Geneva. As there is no standardized dose for cypermethrin, the adopted dose $(0.1 \% / 1 \mathrm{~h})$ which was used by the Instituto Pedro Khouri in Havana, Cuba (Dr Bisset personal communication). Four tests with 100 females in each were exposed to impregnated paper of insecticides and 50 as control, using four and two replicates, respectively. The criteria of interpretation was the one proposed by Davidson and Zahar (1973), and modified by WHO (1998) classifying as "susceptible" insects presenting $98-100 \%$ mortality and "resistant" to mortality as below $80 \%$. An intermediate level would be insects with $80-97 \%$ mortality which corresponds to resistance strongly suspected.

Cluster analysis is an exploratory data analysis tool for solving classification problems by sorting cases into groups, or clusters, so that the degree of association is strong between members of the same cluster and weak between members of different clusters. Each cluster thus describes, in terms of the data collected, the class to which its members belong. The analysis was made using average linkage between groups for larvae RR and adult average mortality percentages to detect natural data groupings, and the distance of field populations from Rockefeller susceptible strain. Cluster analysis was made with SPSS ${ }^{\circledR}$ for Windows.

\section{RESULTS}

Susceptibility of Ae. aegypti larvae to organophosphate insecticides - The LC50 and 95\% estimated were, respectively, for temephos $(2.3$ and $3.4 \mu \mathrm{g} / \mathrm{l})$ and fenitrothion $(2.1$ and $3.8 \mu \mathrm{g} / \mathrm{l})$. In general, the Northeast region populations presented higher RR (between 2.4 and 8.5) than those from SP (between 1.2 and 3.2) as shown in Table I. Comparing different larval populations by cluster analysis allows classification by distance from susceptible strain and characterization of groups with similar susceptibility levels. Fig. 1 shows a dendogram built with data from the RR 95 estimated for the two organophosphates used in the larval control routine (temephos and fenitrothion).

The populations that were grouped close to susceptible Rockefeller came from SP: Bauru, Presidente Prudente, and Marília, with RR below 2. The second group was also composed of only SP populations with RR between 2 and 3. The most distant group from the susceptible strain was formed by populations from counties in Northeast Brazil, where RR were over 3 and only one from SP (Santos), which exhibited the highest resistance level to organophosphates in this state. The most distant population, from Northeast, was Itabaiana, with RR of 8.5 to temephos.

Susceptibility of adult Ae. aegypti populations to organophosphates and pyretroids - Results of bioassays with adults are in Table II. Almost all SP populations were resistant to the two pyretroids insecticides (mortality below 70\%) according to Davidson and Zahar's (1973) criteria, except for Campinas and Marília populations which presented an average mortality of $88 \%$ for cypermethrin. Northeast region populations were more susceptible to pyretroids, except for Itabaiana (permethrin) and Recife (cypermethrin and permethrin). However, no population presented mortality rate above $98 \%$, which would have classified them as susceptible. For organophosphate malathion, the populations with $98 \%$ mortality were from SP (Bauru, Barretos, Marília, and Presidente Prudente). A lower susceptibility level was observed for the Northeast populations: three populations were classified as resistant (Aracaju, Itabaiana, and Recife). In SP, the Ae. aegypti populations from Araçatuba and Santos were considered resistant to malathion. Fig. 2 shows results of cluster analysis with data of percentage of mortality for adults with the organophosphate malathion. Fig. 3 shows the cluster analysis for bioassay results with the two pyretroids on adult mosquitoes. It can be observed that field populations grouped with the susceptible Rockefeller strain came from Northeast (Barra dos Coqueiros, Maceió, Arapiraca, Aracaju, and Jaboatão of Guararapes) where pyretroids had not been introduced until the moment that the field populations were collected, while populations from SP, where cypermethrin had been used for 10 years, were more distant. 


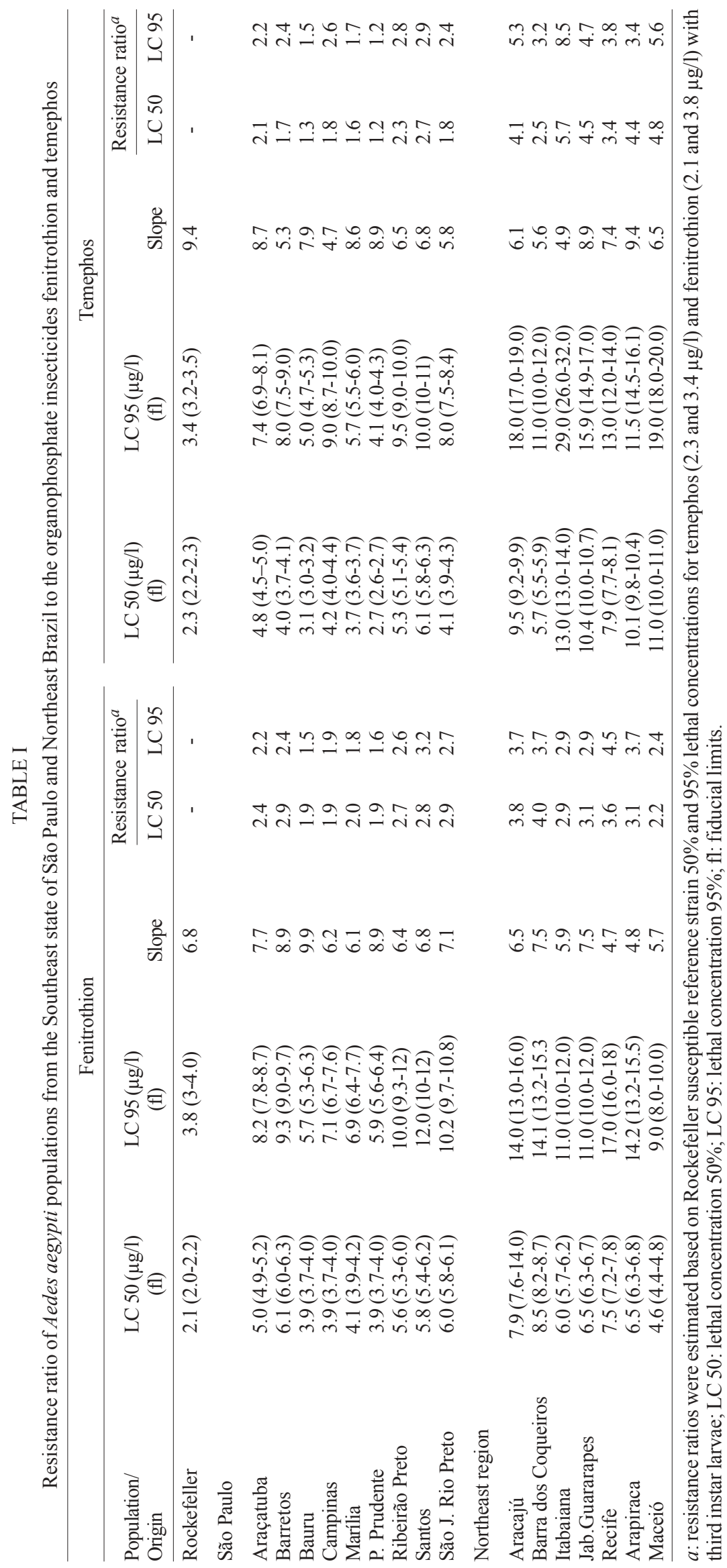




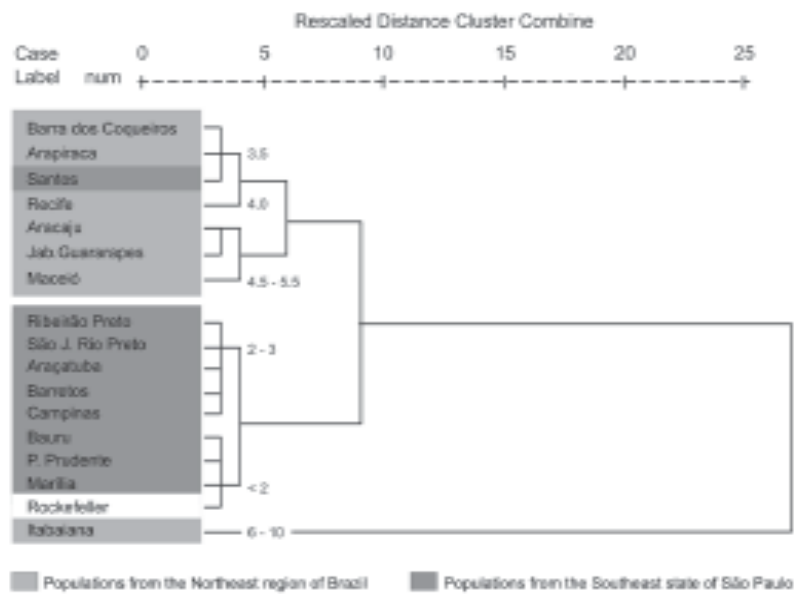

Fig. 1: dendrogram from resistance ratio cluster analysis of Aedes aegypti populations for temephos and fenitrothion.

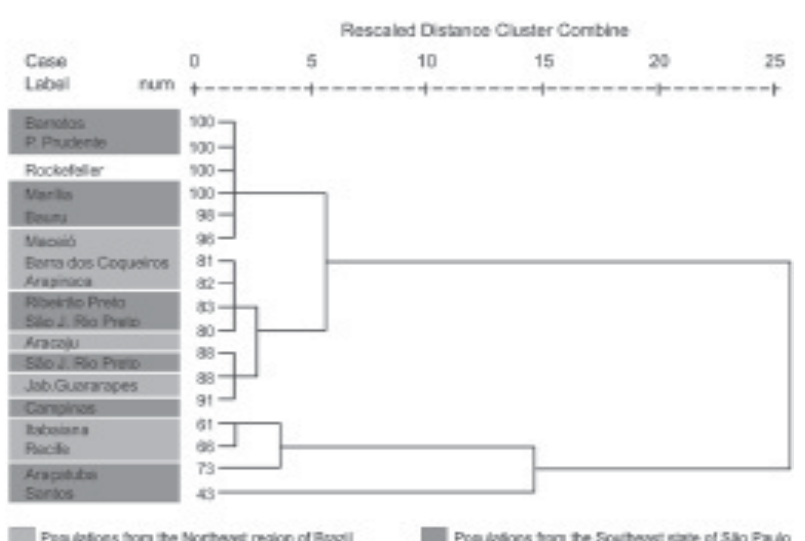

Fig. 2: dendrogram from mortality percentage cluster analysis of Aedes aegypti populations to malathion.

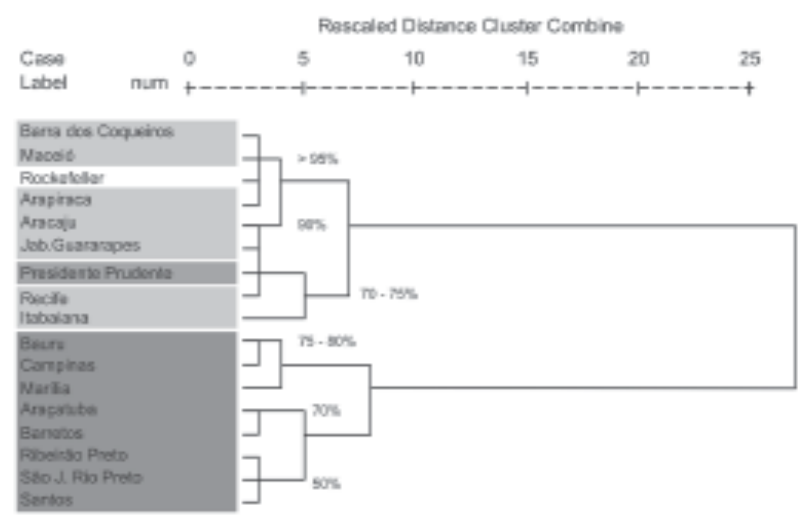

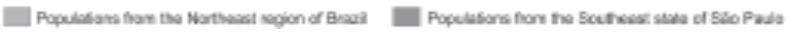

Fig. 3: dendrogram from mortality percentage cluster analysis of Aedes aegypti populations to pyretroids permethrin and cypermethrin.

\section{DISCUSSION}

Evaluation of Ae. aegypti larvae susceptibility to organophosphate insecticides - The most susceptible populations to temephos were Bauru, Marília, and Presidente Prudente, all from SP. Those populations have been presenting that susceptibility level since 1998 (Macoris et al. 1999). Populations from the Northeast region of Brazil presented higher levels of resistance than what was observed in SP. Several colleagues have reported resistance of Ae. aegypti to temephos in many states of Brazil like Espírito Santo (Lima et al. 2003), Rio de Janeiro (Braga et al. 2004). Also from the Northeast region, resistance to temephos seems to be persistent as it was detected more recently in the state of Paraíba with RR (LC90) higher than 10 in three out of six counties (Beserra et al. 2007), and in Ceará (Lima et al. 2006). Santos, the only SP population grouped with populations from the Northeast region, is the city with the highest dengue incidence in the state, which means it has been under high selection pressure through intense use of insecticide. Also, in Santos there is the biggest port in the country, and genetic characterization of $A e$. aegypti showed that this population might have a distinct origin from other populations from SP (Santos 2003, Bracco et al. 2007). In this sense the resistance observed in Ae. aegypti from Santos could be a consequence from intense insecticide use (in epidemics or vector control in the port area). Besides, it may also be inferred that founder populations during reintroducing events through the port of Santos had high insecticide resistance levels. Although resistance levels in the Northeast region are not as high as those in the Caribbean (Rawlins 1998), it is fundamental to check product efficacy under field conditions. Another aspect which concerns about resistance to temephos is the possibility of development of cross resistance. In Cuba, cross resistance to pyretroids induced by selection with temephos in Ae. aegypti has been registered, possibly associated with cytocrome P450 monooxygenase and glutathions-transferase as indicated by synergists studies (Rodriguez et al. 2002). Another study in laboratory with induction of resistance to temephos in Ae. aegypti showed cross resistance to deltamethrirn (Wirth \& Georghiou 1999). As deltamethrin is one choice for adulticide insecticide, the possibility of cross resistance could limit its indication for the regions with resistance to temephos.

Evaluation of Ae. aegypti adult susceptibility to organophosphates and pyretroids - Almost all SP populations were resistant to pyretroid insecticides (cypermethrin and permethrin) after ten years of use. The distance from the susceptible reference strain was proportional to intensity of dengue transmission in the counties where the Ae. aegypti populations were collected, which indirectly reflects insecticide use intensity (Fig. 2). Populations that were grouped further than the Rockefeller susceptible strain were the ones where Dengue incidence was higher in SP, at this order: Santos, São José do Rio Preto, Ribeirão Preto, Barretos, and Araçatuba. At an intermediate distance were grouped the 
TABLE II

Average mortality percentage of Aedes aegypti adult females from the Southeast state of São Paulo and Northeast Brazil to cypermethrin, permethrin and malathion

\begin{tabular}{lccc}
\hline Populations & Cypermethrin & Permethrin & Malathion \\
\hline & $0.1 \%$ 1 hour & $0.25 \%$ 1 hour & $0.8 \% 1$ hour \\
\hline Rockefeller & 99.0 & 98.4 & 99.5 \\
São Paulo & & & 73.0 \\
Araçatuba & 71.7 & 7.5 & 98.3 \\
Bauru & 74.7 & 25.3 & 100 \\
Barretos & 71.4 & 5.0 & 91.4 \\
Campinas & 88.0 & 26.3 & 99.7 \\
Marília & 87.7 & 41.0 & 100 \\
Presidente Prudente & 72.8 & 69.0 & 82.6 \\
Ribeirão Preto & 56.4 & 6.7 & 88.3 \\
São Jose Rio Preto & 50.1 & 10.0 & 42.6 \\
Santos & 42.2 & 12.0 & \\
Northeast region & & & 81.3 \\
Aracaju & & 95.4 & 61.0 \\
Barra dos Coqueiros & 80.3 & 95.3 & 81.7 \\
Itabaiana & 90.4 & 59.5 & 96.3 \\
Arapiraca & 93.0 & 94.3 & 87.5 \\
Maceió & 97.0 & 94.3 & 66.3 \\
Jaboatão & 90.0 & 99.0 & \\
Guararapes & 76.3 & 79.0 & \\
Recife & 75.9 & & \\
\hline & & & \\
\hline
\end{tabular}

populations from the cities where dengue incidence was low: Marilia, Campinas, Bauru, and Presidente Prudente. Northeast region populations still presented high susceptibility levels to this group with the exception of Recife, Jaboatão of Guararapes (Pernambuco), and Itabaiana (Sergipe). As these populations had high resistance levels to temephos, the lower susceptibility to pyretroids could be due to the phenomenon of cross resistance as described by Wirth and Georghiou (1999). The low resistance levels to pyretroids in SP led to management efforts with the substitution of that group by malathion in 2001. Affter the introduction of pyretroids in the routine of Ae. aegypti control in the other Brazilian states in 1999, the evolution of resistance to this group was detected in 2003 in Rio de Janeiro (Pereirada-Cunha et al. 2005), and Paraná (Luna et al. 2004), indicating that alterations on susceptibility to this class of insecticide develops rather quickly.

Susceptibility to malathion (organophosphate) was much higher in Ae. aegypti populations from SP (grouped with Rockefeller in Fig. 2) than in those from Northeast region, which presented lower mortality levels and samples were grouped further from Rockefeller. The Araçatuba and Santos populations from SP however, had the largest distance from the susceptible population (lowest mortality), and were grouped with the Northeast region populations (Recife and Itabaiana). In Araçatuba and Santos, unlike the other counties in SP, malathion and fenitrothion were used for adult control. In Araçatuba malathion was used for controlling dengue transmission in 1986-1987, while fenitrothion and malathion were used in the harbor area for foci control in Santos.

Influence of the history of insecticide use on Ae. aegypti susceptibility - In SP, where organophosphates were used for larvae and pyretroids for adult control, selection pressure after ten years produced high resistance levels to pyretroids in adults and low levels of resistance to organophosphates in larvae. In Northeast region, where organophosphate insecticides were used over a long period for both larvae and adult control, with pyretroids only being introduced for adult control in 1999, there were higher resistance levels to organophosphates in both larvae and adults, and higher susceptibility to pyretroids in adults by the time of the introduction of this group. The strategy of dengue control with chemicals is threatened by the presence of populations resistant to the insecticides used in Brazil. This should be considered in dengue prevention planning and emphasis should be given to integrated control activities, with insecticide use limited to emergency situations.

\section{REFERENCES}

Beserra EB, Fernandes CRM, Queiroga MFC, Castro Jr FP 2007. Resistência de Populações de Aedes aegypti. (Diptera: $\mathrm{Cu}-$ licidae) ao organofosforado temefós na Paraíba. Neotrop Entomology 36: 303-307.

Bracco JE, Capurro ML, Lourenço-de-Oliveira R, Sallum MAM 2007. Genetic variability of Aedes aegypti in the Americas using a mitochondrial gene: evidence of multiple introductions. Mem Inst Oswaldo Cruz 102: 573-580. 
Braga IA, Lima JBP, Soares SS, Valle D 2004. Aedes aegypti resistance to temephos during 2001 in several municipalities in the states of Rio de Janeiro, Sergipe and Alagoas, Brazil. Mem Inst Oswaldo Cruz 99: 199-203.

Davidson G, Zahar AR 1973. The practical implications of resistance in malaria vectors to insecticides. Bull WHO 49: 475-483.

Funasa - Fundação Nacional de Saúde 1994. Manual de Normas Técnicas - Instruções para pessoal de operações. Fundação Nacional de Saúde, Ministério da Saúde, Brasília, 51 pp.

Funasa - Fundação Nacional de Saúde 1996. Manual de Dengue. Vigilância Epidemiológica e Atenção ao Doente. Fundação Nacional de Saúde, Ministério da Saúde, Brasília, 79 pp.

Funasa - Fundação Nacional de Saúde 2001. Dengue. Instruções para Pessoal de Combate ao Vetor. Manual de Normas Técnicas, 3rd ed., Fundação Nacional de Saúde, Ministério da Saúde, Brasília, 84 pp.

Georghiou GP, Wirth M, Saume F, Knudsen AB 1987. Potential for organophosphate resistance in Aedes aegypti (Diptera: Culicidae) in the Caribbean area and neighboring countries. J Med Entomol 24: 290-294.

Lima EP, Oliveira Filho AMO, Oliveira Lima JW, Ramos Júnior ANR, Cavalcanti LPG, Pontes RJS 2006. Resistência do Aedes aegypti ao temefós em municípios do estado do Ceará. Rev Soc Bras Med Trop 39: 259-263.

Lima JB, Pereira da Cunha M, Carneiro da Silva R, Galardo AKR, Soares SS, Braga IA, Ramos RP, Valle D 2003. Resistance of Aedes aegypti to organophosphates in several municipalities in the state of Rio de Janeiro and Espirito Santo, Brazil. Am J Trop Med Hyg 68: 329-333.

Luna JED, Martins MF, Anjos AF, Kuwabara EF, Navarro-Silva MA 2004. Susceptibilidade de Aedes aegypti aos inseticidas temephos e cipermetrina, Brasil. Rev Saúde Públ 38: 842-843.

Macoris MLG, Andrighetti MTM, Takaku L, Glasser CM, Garbeloto VC, Bracco JE 2003. Resistance of Aedes aegypti from the state of São Paulo, Brazil to organophosphates insecticides. Mem Inst Oswaldo Cruz 98: 703-708.

Macoris MLG, Andrighetti MTM, Takaku L, Glasser CM, Garbelotto VC, Cirino VCB 1999. Alteração de resposta de suscetibilidade de Aedes aegypti a inseticidas organofosforados em municípios do estado de São Paulo, Brasil. Rev Saúde Públ 33: 521-522.

Pereira-da-Cunha M, Lima JBP, Brogdon WG, Moya GEM, Valle D 2005. Monitoring of resistance to the pyrethoid cypermethrin in Brazilian Aedes aegypti (Diptera: Culicidae) populations collected between 2001 and 2003. Mem Inst Oswaldo Cruz 100: 441-444.

Leora Software 1987. Polo-PC-a user's guide to Probit or logit analysis. Berkeley, CA.

Rawlins SC 1998. Spatial distribution of insecticide resistance in Caribbean populations of Aedes aegypti and its significance. Rev Panam Salud Públ 4: 243-251.
Reiter P, Amador MA, Colon N 1991. Enhancement of the CDC ovitrap with hay infusions for daily monitoring of Aedes aegypti populations. J Am Mosq Control Assoc 7: 52-55.

Robertson JL, Preisler HK 1992. Pesticide Bioassays with Arthropods. In HK Priesler, R Russel, JL Robertson, CRC Press, Boca Raton, Florida, 127 pp.

Rodriguez MM, Bisset J, Ruiz M, Soca A 2002. Cross-resistance to pyrethroid and organophosphorus insecticides induced by selection with temephos in Aedes aegypti (Diptera: Culicidae) from Cuba. J Med Entomol 39: 882-888.

Santos VM, Macoris MLG, Andrighetti MTM, Avila PE, Kirchgatter K 2003. Analysis of genetic relatedness between populations of Aedes aegypti from different geographic regions of São Paulo State, Brazil. Rev Inst Med Trop São Paulo 45: 99-101.

Sucen - Superintendência de Controle de Endemias 1997. Plano de erradicação de Aedes aegypti. Guia de Instruções, Secretaria de Estado da Saúde de São Paulo, São Paulo, 47 pp.

Sucen - Superintendência de Controle de Endemias 2002. Normas e Recomendações técnicas para Vigilância e Controle do Aedes aegypti, Governo do Estado de São Paulo, São Paulo, 70 pp.

WHO - World Health Organization 1981a. Criteria and Meaning of Tests for Determining the susceptibility or Resistance of Insects to insecticides, WHO/VBC/81.6, Geneva, $4 \mathrm{pp}$.

WHO - World Health Organization 1981b. Instructions for determining the suscetibility or resistance of adult mosquitoes to organochlorine, organophosphate and carbamate insecticides - Diagnostic tests, WHO/VBC/81.806, Geneva, 6 pp.

WHO - World Health Organization 1981c. Instructions for determining the susceptibility or resistance of adult mosquitoes to organochlorine, organophosphate and carbamate insecticides. Establishment of the baseline, WHO/ VBC/81.805, Geneva, 6 pp.

WHO - World Health Organization 1981d. Instructions for determining the susceptibility or resistance of mosquito larvae to insecticides, WHO/VBC/81.807, Geneva, $6 \mathrm{pp}$.

WHO - World Health Organization 1992. Expert Committee on Vector Biology and Control. Vector resistance to pesticides, 818 report, WHO technical report series, Geneva, 63 pp.

WHO - World Health Organization 1998. Test procedures for insecticide resistance monitoring in malaria vectors, bioefficacy and persistence of insecticides on treated surfaces, WHO/CDS/CPC/ MAL/98.12, Geneva, 43 pp.

Wirth MC, Georghiou GP 1999. Selection and characterization of temephos resistance in a population of Aedes aegypti from Tortola, Virgin Islands. J Am Mosquito Control Assoc 15: 315-320. 